\title{
Research on the Relationship between Learning Engagement and Learning Completion of Online Learning Students
}

\author{
https://doi.org/10.3991/ijet.v17i01.28545 \\ Wenjing You \\ Youth College of Political Science of Inner Mongolia Normal University, Inner Mongolia, \\ China \\ youwenjing@imnu. edu.cn
}

\begin{abstract}
With the deep integration of the Internet and education, new educational models, such as micro classrooms, large-scale open online courses, and flipped classrooms have gradually appeared. In the information age, online learning has become popular in most countries all over the world, especially in the face of public crises such as the COVID-19 pandemic. Online learning can effectively connect teachers and students through the Internet. However, the low participation and low cognitive level of e-learning also affect the quality of e-learning, which depends largely on the learning investment of students. Based on selfefficacy theory and exploratory community theory, this paper puts forward the hypothesis that students' e-learning investment affects learning completion and tests the mediating effect of incorporating self-efficacy into students' e-learning investment on learning completion. The results show that the Cronbach's $\alpha$ coefficient is 0.968 , which has high reliability. KMO value is 0.880 , indicating that data information can be extracted effectively. The three aspects of students' elearning input (behavioral investment, cognitive input, and emotional input) constructed in this paper can significantly improve the learning completion level of students. The results of this study have positive value for understanding the advantages and disadvantages of e-learning, promoting the reform of e-learning methods in universities, and implementing e-learning strategies for students familiar with different e-learning years.
\end{abstract}

Keywords_-online learning, student, learning input, learning completion

\section{$1 \quad$ Introduction}

With the advent of the information age, online learning has become popular in most countries all over the world, especially in the face of public crises, such as the COVID19 pandemic. Online learning can effectively connect teachers and students through the Internet. The development of $5 \mathrm{G}$ technology and real-time communication technology provides technical support for the construction of an online learning environment. At present, the mainstream online learning methods in China include online learning based on online platforms such as Nail and Tencent Conference, with live broadcast and video 
lessons as the main forms. These platforms have become important learning channels for learners. The "quality revolution" of online education in China has come. However, with the large-scale practice of new online learning methods represented by MOOCs, the problems of high dropout rate and low participation of online learning have become prominent. The methods for effectively promoting learning completion and improving learning performance has also attracted increasing attention in the academic community. The research on how to promote the efficient transformation of online learning investment into learning effect has become a hotspot in the field of online education.

A large number of studies have shown that online learning investment is malleable. Appropriate teacher teaching intervention, good online learning design, and positive interaction feedback between teachers and students can increase students' learning investment. To strengthen the understanding of the quality of online learning of students, it is necessary to evaluate the level of online learning input of students, help teachers and researchers improve course content, predict and prevent dropouts and improve learning performance. With the development of learning analysis and big data technology in recent years, the related research on learning input evaluation in online education has grown rapidly, and has been developing towards the direction of in-depth evaluation. The evaluation methods are becoming diversified and innovative, and log file analysis and questionnaire analysis have become the most commonly used methods to evaluate learners' online behavior input. Therefore, through the evaluation of emotional and cognitive investment, evaluation through physiological sensor data analysis and computer vision data analysis has also become a potential channel to further explore the relationship between students' online learning investment and learning completion. This study reviews the relevant literature on online learning investment at home and abroad and then analyzes and discusses the methods of evaluating online learning investment, to provide a theoretical basis for the evaluation operation of online learning investment.

\section{Basic theory and hypothesis put forward}

\subsection{Basic theory}

Self-efficacy is an important concept that has emerged with the development of modern pedagogy and psychology, and has been widely accepted globally. At present, the definition of self-efficacy refers mainly to an individual's expectation of his ability to complete a specific behavior in a specific environment. Bandura found that in the process of comprehensively reviewing previous studies [5], an individual should have an intermediate variable in the process of transforming learned knowledge and skills into specific behaviors, which is affected by cognitive psychology. In 1977, he named this intermediary variable "self-efficacy". This intermediary variable consists of two parts, namely efficacy expectations and outcome expectations. Effectiveness expectations refer to the subjective judgment of an individual's ability to perform a specific behavior before acting. Some scholars also define efficacy expectations as an individual's belief in performing a certain behavior or completing a certain task in a specific situation. In 
most studies, efficacy expectation is the main connotation of self-efficacy, and Bandura also believes that self-efficacy will affect an individual's subjective choices and efforts and their attribution of results [3].

D.R. Garrison and Terry Anderson jointly founded the theory of inquiry community [4], which has been widely studied and applied. This theory constructs the inquiry community framework of the face-to-face environment, online environment, and mixed learning environment, which provides enlightened thinking for constructing relevant research models of online learning and making research assumptions. This theory holds that social existence includes open communication, emotional expression, and group cohesion. Online learning makes the whole inquiry community a good learning environment through the creation of curriculum content, design of good learning activities, and strengthening supervision and feedback. The process of online learning is that students realize students' understanding and acquisition of knowledge by implementing appropriate learning strategies. Therefore, exploring community theory also provides a theoretical basis for proposing relevant research hypotheses in this paper.

\subsection{Hypothesis proposal}

With the development of the information age, the connotation and index composition of online learning input have been widely studied, and many research results have been obtained. From early attention to learning state to attention to learning behavior and cognitive state to attention to learning emotional experience, many scholars have focused on present, researchers have focused on the social interaction of online learning and put forward the dimension of social engagement. Therefore, based on the original research, this paper also considers that behavioral investment, cognitive investment, and emotional investment have become the main channels of online learning investment.

Regarding the relationship between behavioral engagement and learning completion, Lane showed that the more students are engaged in classroom behavior, the more students achieve excellent results [5]. Gregory used a randomized controlled design to study the classroom behavior of middle school students [6]. The study showed that student behavioral input is a key condition for supporting academic achievement. Nguyen reported that students' behavior participation changed with the change of environment [7], and the interaction between students and teachers can significantly improve students' learning performance. Downer investigated the influence of classroom quality and teaching environment on third-grade children's behavior participation in class [8]. The results showed that children were more likely to participate in group activities and analytical reasoning teaching. Ponitz investigated the extent to which kindergarten teachers' classroom behavior participation regulates the relationship between the overall classroom quality and children's reading performance [9]. The research shows that rich and positive interaction can effectively attract children to predict literacy performance. Cappella showed that students' higher behavioral participation can achieve more effective management and improve attention [10]. Bryce reported that parents and teachers are the primary socialists of primary school students in all grades [11]. The interaction between teachers and parents can improve pupils' behavior investment in 
the classroom and make them pay more attention to learning. Engels investigated the association between adolescents' behavioral participation and teacher-student relationship during middle school education [12]. The results show that the teacher-student relationship and peer status have a one-way effect on student behavioral investment. Li reported that e-learning methods can better promote high-level learning effects such as innovative thinking and critical thinking [13]. Lan investigated the differences in behavioral participation of Chinese and American students in mathematics classrooms and found that group size and teacher guidance can effectively enhance students' classroom participation and promote effective classroom behaviors [14]. Therefore, this paper proposes the following hypothesis.

H1: Behavioral investment can significantly positively promote the completion of students' learning.

On the relationship between cognitive engagement and learning completion, Corno mainly analyzed the concept of students' cognitive participation [15], and found that students' cognitive participation played a positive role in the learning process and learning results. E studied the relationship between students' cognitive involvement and course achievement and determined that performance goals were positively correlated with shallow cognitive involvement [16], and meaningful cognitive participation restrained the negative effect of shallow participation on achievement. Chi showed that students participated more in learning materials, from passive to active, from constructive to interactive [17], their academic performance will increase. Greene tested the effects of self-efficacy on students' cognitive input and achievement [18]. The results show that students' cognitive input into classroom structure is very important to their motivation and affects the quality of their classroom homework. Richardson found that students gain more experience in online learning, they also have more cognitive input, which makes them begin to take more responsibility for their learning [19]. Joo showed that with a distance education background, students' good cognitive participation has a positive effect on learning outcomes [20]. Seckman reported that Internet-based learning environment is a popular teaching delivery method that provides flexibility, accessibility [21], convenience, and autonomous learning. Internet-based learning has been criticized because it is viewed to cause a lack of community and a lack of the ability to engage students fully, leading to negative learning outcomes. This descriptive relevance study evaluated the relationship between community perception, cognitive participation, and learning outcomes of nursing undergraduates enrolled in Internet-based learning courses. In a convenience sample, 96 undergraduate nursing students participated in the online health informatics course. The results showed that students have a moderate sense of community, and a positive relationship between student participation and learning outcomes can be observed. Various group activities, such as wikis, blogs, and discussion boards, all help to promote community awareness, but students stress that they want more teacher feedback and interaction. Nursing is a cooperative profession, and community building is a key skill. Therefore, innovative teaching/learning techniques are necessary to promote a sense of belonging and community, improve learning outcomes, prepare students for providing quality patient care, and interact with interdisciplinary teams. Li showed that students exhibit various forms of cognitive participation, and the students with better cognitive involvement will perform better in class 
[22]. Dogan evaluated the degree of influence of students' cognitive engagement on academic performance [23], and the results showed that cognitive engagement could predict academic performance. Therefore, this paper puts forward hypothesis $\mathrm{H} 2$.

H2: Cognitive input can significantly and positively promote students' learning completion.

On the relationship between emotional engagement and learning completion. Sagayadevan examined the relationship between emotional input and academic performance and found that emotional input failed to mediate between teacher-student interaction and academic performance but it played an intermediary role between teacher-student interaction and student learning [24], emphasizing the importance of emotional participation in improving students' academic performance. Renshaw showed that the emotional involvement of students is closely related to the results of the transcript [25]. Wara reported that emotional investment can reduce problem behaviors and bad behaviors of middle school students and that by applying game-like design to video teaching systems [26], this approach can significantly enhance emotional participation in learning, thereby improving educational achievement. Gonida analyzed the various effects of middle school students' behavior and emotional investment in the classroom on students' mastery of learning goals [27] [28]. Shih showed that students with more emotional involvement will participate in their studies more fully [29]. Compared with behavioral participation students with lower emotional involvement levels, behavioral participation students with higher emotional involvement levels have a higher perception of autonomous support from teachers, recognition rules, intrinsic motivation, and goal orientation of mastering methods. Mih analyzed the role of emotional participation in mediating the relationship between achievement goals and some dimensions of school adaptation and found that emotional participation is closely related to performance goals [30]. Garn (2017) found that emotional involvement is a predictor of control and external value evaluation, as well as happiness and boredom [31]. Therefore, this paper puts forward hypothesis $\mathrm{H} 3$.

H3: Emotional involvement can significantly positively promote students' learning completion.

Research literature has shown that students' self-efficacy can affect their learning performance [32] (Chen (2017) [33], Lorenzet (2005) [34], Chang (2014), [35] Lee (2016)[36], and Arnold (2009)[37], etc.). Studies have also shown that students' better self-efficacy can promote them to complete their learning and improve their learning performance. Therefore, this paper proposes hypothesis $\mathrm{H} 4$.

H4: Self-efficacy plays an intermediary role in the significant positive effect of online learning investment on students' learning completion.

\section{$3 \quad$ Research design}

\subsection{Questionnaire design}

This study referred to the existing measurement standards and tools of online learning engagement and online learning completion and focused on the new changes of the 
online learning process and learning results of students given the learning characteristics of Chinese students under the influence of epidemic situations. Under the guidance of the education professor, the author's research group compiled the questionnaire on "online learning engagement and learning completion of students", with a total of 28 questions. The questionnaire is divided into three parts. The first part is "basic information of learners", which consists of four items. The second part is the measurement of online learning investment. This paper also uses the widely used online learning investment scale (student engagement in distance education, Sede) compiled by Sun (XXXX) and (Rueda 2012) to measure online learning investment [1]. This scale includes three items of behavioral investment, five items of cognitive investment, and seven items of emotional investment, a total of 15 items. The third part is the mediating variable (self-efficacy). Based on the questionnaire of Luszczynska [2], six topics are selected as the questionnaire options of this paper. For the learning completion degree, this article redesigned three topics based on discussions with education experts to be more in line with the actual situation of undergraduates in ordinary universities in China. All items are designed using Likert's 5-point scale.

\subsection{Research object}

In September 2021, the authors investigated the undergraduates of a provincial university in Shandong Province. As one of the specific task undertaking units of the Shandong Education Informatization 2.0 Action Plan (2019-2022), the mixed teaching reform has achieved remarkable results since 2019 and has achieved rich information teaching reform projects. The university has widely used China's mainstream mobile terminal-based smart teaching platforms, such as Rain Classroom, Blue Moyun Class, Wisdom Vocational Education, and Wisdom Tree, etc. All courses have undergone online and offline hybrid teaching reforms, and all full-time teachers can complete online teaching. Students can also maintain a balance between online learning and offline learning time, and often interact with teachers and classmates through social media platforms (such as QQ, campus BBS, WeChat, etc.). In this survey, some professional teachers of the university distributed paper questionnaires in their respective classes. A total of 239 questionnaires were returned. After excluding blank and invalid questionnaires, 186 valid questionnaires were retained. The questionnaire response rate was $77.82 \%$. After careful editing by the research team, the questionnaire answers were input into the SPSS22.0 software. The descriptive results of the research objects in this paper are shown in Table 1.

Table 1. Descriptive results of respondents

\begin{tabular}{|c|c|c|c|c|}
\hline \multirow{2}{*}{ Name } & Option & Frequency & Percentage (\%) & $\begin{array}{c}\text { Cumulative } \\
\text { percentage (\%) }\end{array}$ \\
\hline \multirow{2}{*}{ Gender } & Man & 114 & 61.29 & 61.29 \\
\cline { 2 - 5 } & Woman & 72 & 38.71 & 100 \\
\hline \multirow{2}{*}{ Grade } & Grade 1 & 7 & 3.76 & 3.76 \\
\cline { 2 - 5 } & Grade 2 & 52 & 27.96 & 31.72 \\
\hline
\end{tabular}


Paper-Research on the Relationship between Learning Engagement and Learning Completion of...

\begin{tabular}{|l|c|c|c|c|}
\hline \multirow{4}{*}{} & Grade 3 & 73 & 39.25 & 70.97 \\
\cline { 2 - 5 } & Grade 4 & 54 & 29.03 & 100 \\
\hline \multirow{4}{*}{ Subject } & History & 3 & 1.61 & 1.61 \\
\cline { 2 - 5 } & Economics & 32 & 17.2 & 18.82 \\
\cline { 2 - 5 } & Management & 63 & 33.87 & 52.69 \\
\cline { 2 - 5 } & Education & 64 & 34.41 & 87.1 \\
\hline \multirow{4}{*}{$\begin{array}{l}\text { Years of } \\
\text { familiarity with } \\
\text { online learning }\end{array}$} & Philosophy & 24 & 12.9 & 100 \\
\cline { 2 - 5 } & Less than 0.5 years & 43 & 23.12 & 23.12 \\
\cline { 2 - 5 } & 0.5 year-1 year & 18 & 9.68 & 32.8 \\
\cline { 2 - 5 } & 1 year-2 years & 40 & 21.51 & 54.3 \\
\hline Total & 2-5 years & 24 & 12.9 & 67.2 \\
\hline
\end{tabular}

\section{$4 \quad$ Result analysis}

\subsection{Reliability and validity analysis}

Reliability analysis is used to study the reliability and accuracy of quantitative data. First, the Cronbach's $\alpha$ coefficient is analyzed. If this value is higher than 0.8 , it means that the reliability is high. If the value is between 0.7 and 0.8 , the reliability is good. If this value is between 0.6 and 0.7 , the reliability is acceptable. If this value is less than 0.6 , the reliability is poor.

Table 2 shows that the Cronbach's $\alpha$ coefficient is 0.968 , which is greater than 0.9 , indicating that the reliability of the research data is of high quality. Regarding the "CITC value", the CITC values of the analysis items are all greater than 0.4 , indicating a good correlation between the analysis items and a good level of reliability. In summary, the reliability coefficient value of the research data is higher than 0.9 , which comprehensively shows that the reliability of the data is of high quality.

Table 2. Reliability test results

\begin{tabular}{|c|c|c|c|c|c|}
\hline Variable name & $\begin{array}{c}\text { Option } \\
\text { name }\end{array}$ & $\begin{array}{c}\text { Total correlation of } \\
\text { correction terms(CITC) }\end{array}$ & $\begin{array}{l}\text { Item deleted } \\
\alpha \text { coefficient }\end{array}$ & $\begin{array}{c}\text { Cronbach } \alpha \\
\text { coefficient }\end{array}$ & $\begin{array}{l}\text { Cronbach } \alpha \\
\text { coefficienty }\end{array}$ \\
\hline \multirow{3}{*}{$\begin{array}{l}\text { Behavioral engagement } \\
\text { A }\end{array}$} & A1 & 0.686 & 0.822 & \multirow{3}{*}{0.784} & \multirow{9}{*}{0.968} \\
\hline & $\mathrm{A} 2$ & 0.763 & 0.619 & & \\
\hline & A3 & 0.743 & 0.566 & & \\
\hline \multirow{5}{*}{$\begin{array}{l}\text { Cognitive input } \\
\text { B }\end{array}$} & B1 & 0.192 & 0.702 & \multirow{5}{*}{0.661} & \\
\hline & B2 & 0.172 & 0.708 & & \\
\hline & B3 & 0.591 & 0.523 & & \\
\hline & B4 & 0.578 & 0.523 & & \\
\hline & B5 & 0.584 & 0.525 & & \\
\hline Emotional engagement $\mathrm{C}$ & $\mathrm{C} 1$ & 0.89 & 0.931 & 0.946 & \\
\hline
\end{tabular}




\begin{tabular}{|c|c|c|c|c|}
\hline & $\mathrm{C} 2$ & 0.847 & 0.935 & \\
\hline & $\mathrm{C} 3$ & 0.635 & 0.953 & \\
\hline & $\mathrm{C} 4$ & 0.778 & 0.941 & \\
\hline & $\mathrm{C} 5$ & 0.845 & 0.935 & \\
\hline & C6 & 0.819 & 0.937 & \\
\hline & $\mathrm{C} 7$ & 0.927 & 0.928 & \\
\hline & $\mathrm{Y} 1$ & 0.799 & 0.594 & \\
\hline Learning completion $\mathrm{Y}$ & $\mathrm{Y} 2$ & 0.719 & 0.669 & 0.808 \\
\hline & Y3 & 0.481 & 0.907 & \\
\hline & M1 & 0.655 & 0.924 & \\
\hline & M2 & 0.884 & 0.891 & \\
\hline Self-efficacy M & M3 & 0.842 & 0.897 & 0.921 \\
\hline & M4 & 0.75 & 0.912 & 0.921 \\
\hline & M5 & 0.798 & 0.904 & \\
\hline & M6 & 0.764 & 0.908 & \\
\hline
\end{tabular}

Validity analysis is used to study the design rationality of quantitative data (especially attitude scale). First, the KMO value is analyzed. If this value is higher than 0.8 , it means the validity is high, whereas if the value is between 0.7 and 0.8 , the validity is good. If this value is between 0.6 and 0.7 , it means that the validity is acceptable and if it is less than 0.6 , it means that the validity is not good. Table 3 shows that the common degree values corresponding to all research items are higher than 0.4 , indicating that the research item information can be effectively extracted. In addition, the KMO value is 0.880 , which is greater than 0.6 , indicating that the data information can be effectively extracted. In addition, the variance interpretation rate values of the six factors are $30.589 \%, 24.271 \%, 19.129 \%, 4.567 \%, 4.432 \%$, and $4.296 \%$, and the cumulative variance interpretation rate after rotation is $87.283 \%>50 \%$. It means that the amount of information on the research item can be extracted effectively.

Table 3. KMO and Bartlett's test

\begin{tabular}{|c|c|c|c|c|c|c|c|}
\hline \multirow[t]{2}{*}{ Name } & \multicolumn{6}{|c|}{ Factor load coefficient } & \multirow{2}{*}{\begin{tabular}{|c} 
Common degree \\
(common factor \\
variance)
\end{tabular}} \\
\hline & Factor1 & Factor2 & Factor3 & Factor4 & Factor5 & Factor6 & \\
\hline A1 & 0.179 & 0.145 & 0.22 & 0.136 & 0.863 & -0.118 & 0.878 \\
\hline A2 & 0.521 & 0.27 & 0.563 & -0.011 & 0.067 & 0.125 & 0.682 \\
\hline A3 & 0.325 & 0.591 & 0.558 & -0.036 & 0.108 & -0.035 & 0.78 \\
\hline B1 & 0.044 & -0.031 & 0.061 & 0.901 & 0.119 & 0.216 & 0.879 \\
\hline B2 & 0.004 & 0.016 & 0.069 & 0.212 & -0.103 & 0.913 & 0.893 \\
\hline B3 & 0.462 & 0.793 & 0.263 & 0.01 & 0.146 & 0.02 & 0.933 \\
\hline B4 & 0.471 & 0.257 & 0.597 & 0.245 & 0.012 & 0.001 & 0.704 \\
\hline B5 & 0.253 & 0.78 & 0.443 & -0.092 & 0.117 & 0.115 & 0.905 \\
\hline $\mathrm{C} 1$ & 0.669 & 0.358 & 0.551 & 0.087 & 0.073 & -0.026 & 0.892 \\
\hline $\mathrm{C} 2$ & 0.465 & 0.793 & 0.26 & 0.007 & 0.147 & 0.015 & 0.935 \\
\hline $\mathrm{C} 3$ & 0.184 & 0.201 & 0.906 & 0.032 & 0.114 & 0.03 & 0.91 \\
\hline
\end{tabular}


Paper-Research on the Relationship between Learning Engagement and Learning Completion of...

\begin{tabular}{|c|c|c|c|c|c|c|c|}
\hline $\mathrm{C} 4$ & 0.255 & 0.782 & 0.444 & -0.097 & 0.128 & 0.111 & 0.912 \\
\hline C5 & 0.812 & 0.34 & 0.337 & 0.13 & -0.055 & -0.032 & 0.909 \\
\hline C6 & 0.846 & 0.319 & 0.234 & -0.058 & 0.184 & 0.089 & 0.917 \\
\hline C7 & 0.67 & 0.513 & 0.421 & 0.108 & 0.031 & -0.01 & 0.903 \\
\hline Y1 & 0.837 & 0.374 & 0.288 & 0.11 & -0.017 & -0.075 & 0.941 \\
\hline $\mathrm{Y} 2$ & 0.614 & 0.496 & 0.2 & 0.233 & -0.104 & -0.216 & 0.774 \\
\hline $\mathrm{Y} 3$ & 0.17 & 0.275 & 0.869 & 0.016 & 0.158 & 0.022 & 0.886 \\
\hline M1 & 0.317 & 0.872 & 0.041 & 0.076 & -0.075 & -0.099 & 0.884 \\
\hline M2 & 0.837 & 0.372 & 0.287 & 0.105 & -0.02 & -0.083 & 0.939 \\
\hline M3 & 0.461 & 0.764 & 0.352 & 0.04 & 0.107 & -0.004 & 0.932 \\
\hline M4 & 0.837 & 0.278 & 0.014 & -0.08 & 0.192 & 0.023 & 0.823 \\
\hline M5 & 0.845 & 0.18 & 0.231 & -0.087 & 0.24 & 0.109 & 0.877 \\
\hline M6 & 0.557 & 0.366 & 0.64 & 0.048 & 0.03 & 0.045 & 0.859 \\
\hline Eigenvalue (before rotation) & 14.825 & 1.77 & 1.57 & 1.169 & 0.88 & 0.733 & - \\
\hline $\begin{array}{l}\text { Variance explanation rate } \% \\
\text { (before rotation) }\end{array}$ & $\begin{array}{c}61.769 \\
\%\end{array}$ & $7.375 \%$ & $6.543 \%$ & $4.871 \%$ & $3.668 \%$ & $3.056 \%$ & - \\
\hline $\begin{array}{l}\text { Cumulative variance inter- } \\
\text { pretation rate\% (before rota- } \\
\text { tion) }\end{array}$ & $\begin{array}{c}61.769 \\
\%\end{array}$ & $69.144 \%$ & $75.687 \%$ & $\begin{array}{c}80.559 \\
\%\end{array}$ & $\begin{array}{c}84.227 \\
\%\end{array}$ & $\begin{array}{c}87.283 \\
\%\end{array}$ & - \\
\hline $\begin{array}{l}\text { Feature root value (after rota- } \\
\text { tion) }\end{array}$ & 7.341 & 5.825 & 4.591 & 1.096 & 1.064 & 1.031 & - \\
\hline $\begin{array}{l}\text { Variance explanation rate\% } \\
\text { (after rotation) }\end{array}$ & $\begin{array}{c}30.589 \\
\%\end{array}$ & $24.271 \%$ & $19.129 \%$ & $4.567 \%$ & $4.432 \%$ & $4.296 \%$ & - \\
\hline $\begin{array}{l}\text { Cumulative variance expla- } \\
\text { nation rate } \% \text { (after rotation) }\end{array}$ & $\begin{array}{c}30.589 \\
\%\end{array}$ & $54.860 \%$ & $73.988 \%$ & $\begin{array}{c}78.555 \\
\%\end{array}$ & $\begin{array}{c}82.987 \\
\%\end{array}$ & $\begin{array}{c}87.283 \\
\%\end{array}$ & - \\
\hline KMO value & \multicolumn{6}{|c|}{0.88} & - \\
\hline Bart sphericity & \multicolumn{6}{|c|}{7984.805} & - \\
\hline Df & \multicolumn{6}{|c|}{276} & - \\
\hline$p$ value & \multicolumn{6}{|c|}{0} & - \\
\hline
\end{tabular}

\subsection{Regression analysis}

Table 4 shows the following:

Suppose H1 holds; that is, in online learning, students' behavioral involvement can significantly improve their learning completion. This conclusion is consistent with the conclusions of most research literature. It can be seen an inevitable trend for students is to accept online learning, which solves the problem that offline education cannot be carried out normally during public crises, such as the pandemic. Because China has developed online learning for more than ten years, it is no stranger to current students. Students have good offline study habits, and their online learning completion can be significantly improved by continuously strengthening the study duration, correcting the study attitude, and developing standardized study behaviors. At the same time, their good interpersonal communication (interaction with classmates and teachers) also ensures their good behavior input and promotes their learning performance level to be in a good range. 
Suppose H2 holds. Students' cognitive involvement can significantly improve their learning completion. Their awareness investment mainly comes from their sense of identity for online learning courses. At present, the online learning content of most universities in China is still very good. Many universities have introduced online learning methods, and students' awareness of online learning has increased yearly. Good online learning resources and friendly interactive learning methods make students more willing to increase their cognitive investment. Such online learning resources has fully systematized the training objectives of Chinese students in terms of professional skills. Therefore, universities have been paying attention to ensuring the top-level design of online learning, and indirectly increase the cognitive input of students by enhancing their online learning motivation, stimulating their interest in learning, and encouraging them to participate in online learning in multiple ways.

Assume that $\mathrm{H} 3$ holds. The emotional investment of students can significantly improve their learning completion. Most universities in China have adopted online learning methods. They have also equipped full-time counselors to pay attention to the emotional changes of students' online learning. Students gradually develop the concept of good learning and lifelong learning through humanistic care. In online learning, students with high emotional involvement often show positive emotions, such as curiosity and pleasure, which makes students' emotional involvement more abundant, and finally accelerates the improvement of online learning completion. However, learners with low emotional input are more casual, often showing negative emotions, such as boredom. Emotional involvement has a significant correlation to improving students' learning performance. The stronger the curiosity, pleasure, and sense of belonging of learners to the course, the higher their learning performance and the learners generally show positive emotional experience.

Table 4. Regression results

\begin{tabular}{|c|c|c|c|c|c|c|c|}
\hline & $\begin{array}{c}\text { Standardization } \\
\text { factor }\end{array}$ & $\mathbf{T}$ & $\mathbf{P}$ & VIF & $\mathbf{R}^{2}$ & Adjust $\mathbf{R}^{2}$ & $\mathbf{F}$ \\
\hline Constant & - & 5.21 & $0.000^{* *}$ & - & \multirow{4}{*}{0.706} & \multirow{4}{*}{0.701} & \multirow{4}{*}{$\mathrm{F}(3,182)=145.699, \mathrm{p}=0.000$} \\
\hline \begin{tabular}{|l|} 
Behavioral \\
involvement
\end{tabular} & 0.390 & 6.718 & $0.000^{* *}$ & 2.085 & & & \\
\hline \begin{tabular}{l|} 
Cognitive \\
involvement
\end{tabular} & 0.336 & 5.467 & $0.000^{* *}$ & 2.338 & & & \\
\hline \begin{tabular}{|l|} 
Emotional \\
involvement
\end{tabular} & 0.222 & 3.788 & $0.000^{* *}$ & 2.123 & & & \\
\hline
\end{tabular}

\subsection{Mediating effect analysis}

Table 5 shows that suppose $\mathrm{H} 4$ holds, that is, self-efficacy has a partial mediating effect in that online learning input can significantly positively promote students' learning completion. In online learning behavior, self-efficacy not only affects students' interest, confidence, and belief in success but also plays a decisive role in the final effect of learning. Generally speaking, students with a high sense of self-efficacy will choose to deal with learning difficulties rationally, face them bravely, respond positively, and 
keep the firm belief. When frustrated, those with low self-efficacy choose to avoid challenges, be at a loss, respond passively, avoid problems, and lack enough confidence to overcome difficulties, which leads to a weak belief in success. Students continue to gain a sense of success in online learning to maintain their interest. Therefore, teachers should also pay attention to the cultivation of students' confidence when teaching specific knowledge online. Sense of success is also an important indicator of quality education. Whether students can often experience success has an important effect on their mental health development. Therefore, it also inspired college teachers to teach at different levels in daily online teaching work. According to the differences in each student's learning level, students are organized into different groups, and timely adjustments are made to put forward different requirements for different groups to start teaching gradually.

Table 5. Mediating effect results

\begin{tabular}{|l|c|c|c|}
\hline & Degree of completion & Self-efficacy & Learning completion \\
\hline Constant & $0.998^{* *}(4.250)$ & $1.650^{* *}(6.972)$ & $-0.130(-0.679)$ \\
\hline $\begin{array}{l}\text { Online learning invest- } \\
\text { ment }\end{array}$ & $0.773^{* *}(11.367)$ & $0.633^{* *}(9.238)$ & $0.340^{* *}(5.689)$ \\
\hline Self efficacy & - & - & $0.684^{* *}(12.862)$ \\
\hline Sample size & 186 & 186 & 186 \\
\hline $\mathrm{R}^{2}$ & 0.413 & 0.317 & 0.691 \\
\hline Adjust $\mathrm{R}^{2}$ & 0.409 & 0.313 & 0.688 \\
\hline F value & $\mathrm{F}$ & $\begin{array}{c}\mathrm{F} \\
\mathrm{F}\end{array}$ & \\
\hline
\end{tabular}

${ }^{*} \mathrm{p}<0.05,{ }^{* *} \mathrm{p}<0.01 \mathrm{~T}$ value in parentheses

\subsection{Variance test and T-test}

Table 6 shows that there is no significant difference in the learning completion of students in gender and disciplines. The main reason is that the University, as an ordinary provincial university in Shandong Province, has done a good job in the online teaching reform under the influence of the pandemic. The overall admission score of boys and girls in the school is relatively high, the quality of students is high, and they have accepted the online teaching method well. At the same time, the school has comprehensively promoted and implemented online teaching reforms in different sciences and introduced the implementation methods for online teaching reforms within the school to encourage teachers to implement national first-class online quality courses. Online teaching in all subjects has achieved good results, and thus, no differences were observed in the degree of completion of learning in subjects. 
Paper - Research on the Relationship between Learning Engagement and Learning Completion of...

Table 6. Variance test and T-test

\begin{tabular}{|l|c|c|c|}
\hline & Degree of completion & Self-efficacy & Learning completion \\
\hline Constant & $0.998^{* *}(4.250)$ & $1.650^{* *}(6.972)$ & $-0.130(-0.679)$ \\
\hline $\begin{array}{l}\text { Online learning } \\
\text { investment }\end{array}$ & $0.773^{* *}(11.367)$ & $0.633^{* *}(9.238)$ & $0.340^{* *}(5.689)$ \\
\hline Self efficacy & - & - & $0.684^{* *}(12.862)$ \\
\hline Sample size & 186 & 186 & 186 \\
\hline $\mathrm{R}^{2}$ & 0.413 & 0.317 & 0.691 \\
\hline Adjust $\mathrm{R}^{2}$ & 0.409 & 0.313 & 0.688 \\
\hline F value & $\mathrm{F}(1,184)=129.215, \mathrm{p}=0.000$ & $\mathrm{~F}(1,184)=85.347, \mathrm{p}=0.000$ & $\mathrm{~F}(2,183)=205.068, \mathrm{p}=0.000$ \\
\hline
\end{tabular}

${ }^{*} \mathrm{p}<0.05,{ }^{* *} \mathrm{p}<0.01 \mathrm{~T}$ value in parentheses

Table 7 shows the presence of a typical difference in the grade distribution of online learning completion. From the score point of view, sophomores have the highest online learning completion and seniors have the lowest score. The main reason is that sophomores have experienced the initial acceptance of online learning as freshmen, and fully accepted various skills of online learning, which made them more willing to accept online learning and promoted the improvement of the complete degree of online learning in universities. Meanwhile, because they are busy with finding jobs and writing graduation thesis, senior students need to concentrate more on offline tasks, and thus are unable to concentrate on online learning of senior students and fail to form effective learning completion performance, causing the senior students to score the lowest and online learning completion degree of the whole grade. The degree of online learning completion also shows obvious differences in the number of years that one is familiar with online learning. In terms of scores, students who have been familiar with online learning for $0.5-1$ years have the best online learning completion, while students who have been familiar with online learning for more than 5 years have the lowest lack of scores. The main reason is that although online learning is a mainstream development trend, once students are familiar with online learning skills in senior high school, they become more familiar with online learning skills, and the more likely they are to hang out, find something to replace learning, waste time and cause students to develop dependency, resulting in the decline of learning efficiency. In particular, students have high requirements for autonomous learning ability and self-discipline ability, and the lack of on-site guidance and constraints of teachers and the ease that they can be distracted causes them to have learning burnout, which makes their learning completion score low. Hence, universities have strengthened the online and offline hybrid teaching reform with the overall planning of online teaching because they cannot simply and completely rely on online learning.

Table 7. Variance test results of years and grades familiar with online learning

\begin{tabular}{|c|c|c|c|c|c|c|c|c|}
\hline \multicolumn{7}{|c|}{ Year of familiarity with online learning (mean \pm standard deviation) } & \multirow[t]{2}{*}{$\mathbf{F}$} & \multirow[t]{2}{*}{$\mathbf{p}$} \\
\hline $1.0(\mathrm{n}=43)$ & $2.0(n=18)$ & \multicolumn{2}{|c|}{$3.0(n=40)$} & \multicolumn{2}{|c|}{$4.0(n=24)$} & $5.0(n=61)$ & & \\
\hline $3.65 \pm 0.95$ & $3.89 \pm 0.47$ & \multicolumn{2}{|c|}{$3.27 \pm 1.36$} & \multicolumn{2}{|c|}{$3.79 \pm 0.98$} & $3.13 \pm 1.13$ & 3.285 & $0.013^{*}$ \\
\hline \multicolumn{7}{|c|}{ Grade (mean \pm SD) } & \multirow{2}{*}{$\mathrm{F}$} & \multirow[b]{2}{*}{$\mathrm{p}$} \\
\hline \multicolumn{2}{|l|}{$1.0(\mathrm{n}=7)$} & $2.0(\mathrm{n}=52)$ & \multicolumn{2}{|c|}{$3.0(n=73)$} & \multicolumn{2}{|c|}{$4.0(n=54)$} & & \\
\hline \multicolumn{2}{|l|}{$3.86 \pm 1.35$} & $3.48 \pm 1.15$ & \multicolumn{2}{|c|}{$4.07 \pm 0.99$} & & $3.56 \pm 1.09$ & 3.808 & $0.011^{*}$ \\
\hline
\end{tabular}




\section{Conclusions}

Mobile Internet, artificial intelligence, and information technology have effectively realized the teaching methods of education informatization. The endless network learning platforms and resources ensure the normal learning of students, while also greatly promoting the informatization and modernization of education. With the in-depth application of online learning, the drawbacks of a completely online learning model have gradually been exposed. In the online learning environment, teachers and students conduct teaching and learning through the Internet. Students lack external supervision and their self-management capabilities cannot reach the level of online learning requirements, and thus, the quality of learning cannot be guaranteed. Based on the theory of self-efficacy and the theory of exploratory community, this paper incorporates self-efficacy in online learning as an intermediary variable and designs a survey questionnaire on the effects of students' learning input on learning completion. The results show that the Cronbach's $\alpha$ coefficient is 0.968 and the KMO value is 0.880 , which reflects the good reliability and validity of this paper. Three aspects of students' online learning input (behavioral, cognitive, and emotional input) can significantly improve their learning completion. Self-efficacy has a partial mediating effect in that online learning engagement can significantly and positively promote students' learning completion. No significant difference was observed in the degree of learning completion of students in gender and subject. The degree of online learning completion is significantly different in grades and years when you are familiar with online learning skills. Hence, in the future, we can continue to conduct in-depth research on automatic technology to track and analyze the effect of online learning, collect learning data information to evaluate learners' cognitive input, and the rapid development of information technology will promote the multimodal data evaluation of online learning.

\section{References}

[1] Sun, J. C.Y., Rueda, R. Situational interest, computer self-efficacy and self-regulation: Their impact on student engagement in distance education. British journal of educational technology, 2012, vol. 43(2), pp. 191-204. https://doi.org/10.1111/j.1467-8535.2010.01157.x

[2] Luszczynska, A., Scholz, U., Schwarzer, R. The general self-efficacy scale: multicultural validation studies. The Journal of psychology, 2005, vol. 139(5), pp. 439-457. https://doi. org/10.3200/JRLP.139.5.439-457

[3] Bandura, A. Self-efficacy: toward a unifying theory of behavioral change. Psychological review, 1977, vol. 84(2), pp. 191. https://doi.org/10.1037/0033-295X.84.2.191

[4] Garrison, D. R., Anderson, T., Archer, W. Critical inquiry in a text-based environment: Computer conferencing in higher education. The internet and higher education, 1999, vol. 2(2-3), pp. 87-105. https://doi.org/10.1016/S1096-7516(00)00016-6

[5] Lane, E.S., Harris, S.E. A new tool for measuring student behavioral engagement in large university classes. Journal of College Science Teaching, 2015, vol. 44(6), pp. 83-91.

[6] Gregory, A., Allen, J.P., Mikami, A.Y., Hafen, C.A., Pianta, R.C. Effects of a professional development program on behavioral engagement of students in middle and high school. Psychology in the Schools, 2014, vol. 51(2), pp. 143-163. https://doi.org/10.1002/pits.21741 
Paper-Research on the Relationship between Learning Engagement and Learning Completion of...

[7] Nguyen, T.D., Cannata, M., Miller, J. Understanding student behavioral engagement: Importance of student interaction with peers and teachers. The Journal of Educational Research, 2018, vol. 111(2), pp. 163-174. https://doi.org/10.1080/00220671.2016.1220359

[8] Downer, J.T., Rimm-Kaufman, S.E., Pianta, R.C. How do classroom conditions and children's risk for school problems contribute to children's behavioral engagement in learning?. School Psychology Review, 2007, vol. 36(3), pp. 413-432. https://doi.org/10.1080/027 96015.2007.12087938

[9] Ponitz, C.C., Rimm-Kaufman, S.E., Grimm, K.J., Curby, T.W. Kindergarten classroom quality, behavioral engagement, and reading achievement. School Psychology Review, 2009, vol. 38(1), pp. 102-120. https://doi.org/10.1080/02796015.2009.12087852

[10] Cappella, E., Kim, H.Y., Neal, J.W., Jackson, D.R. Classroom peer relationships and behavioral engagement in elementary school: The role of social network equity. American journal of community psychology, 2013, vol. 52(3-4), pp. 367-379. https://doi.org/10.1007/s10464$\underline{013-9603-5}$

[11] Bryce, C.I., Bradley, R.H., Abry, T., Swanson, J., Thompson, M.S. Parents' and teachers' academic influences, behavioral engagement, and first-and fifth-grade achievement. School Psychology, 2019, vol. 34(5), pp. 492. https://doi.org/10.1037/spq0000297

[12] Engels, M.C., Colpin, H., Van Leeuwen, K., Bijttebier, P., Van Den Noortgate, W., Claes, S., ... \& Verschueren, K. Behavioral engagement, peer status, and teacher-student relationships in adolescence: A longitudinal study on reciprocal influences. Journal of youth and adolescence, 2016, vol. 45(6), pp. 1192-1207. https://doi.org/10.1007/s10964-016-0414-5

[13] Li, F., Qi, J., Wang, G., Wang, X. Traditional classroom vs e-learning in higher education: Difference between students' behavioral engagement. International Journal of Emerging Technologies in Learning, 2014, vol. 9(2), pp. 48-51. https://doi.org/10.3991/ijet.v9i2.3268

[14] Lan, X., Ponitz, C.C., Miller, K.F., Li, S., Cortina, K., Perry, M., Fang, G. Keeping their attention: Classroom practices associated with behavioral engagement in first grade mathematics classes in China and the United States. Early Childhood Research Quarterly, 2013, vol. 24(2), pp. 198-211. https://doi.org/10.1016/j.ecresq.2009.03.002

[15] Corno, L., Mandinach, E.B. The role of cognitive engagement in classroom learning and motivation. Educational psychologist, 1983, vol. 18(2), pp. 88-108. https://doi.org/10.1080/ $\underline{00461528309529266}$

[16] Greene, B.A., Miller, R.B. Influences on achievement: Goals, perceived ability, and cognitive engagement. Contemporary Educational Psychology, 1996, vol. 21(2), pp. 181-192. https://doi.org/10.1006/ceps.1996.0015

[17] Chi, M.T., Wylie, R. The ICAP framework: Linking cognitive engagement to active learning outcomes. Educational psychologist, 2014, vol. 49(4), pp. 219-243. https://doi.org/10.1080/ $\underline{00461520.2014 .965823}$

[18] Greene, B.A., Miller, R.B., Crowson, H.M., Duke, B.L., Akey, K.L. Predicting high school students' cognitive engagement and achievement: Contributions of classroom perceptions and motivation. Contemporary educational psychology, 2004, vol. 29(4), pp. 462-482. https://doi.org/10.1016/j.cedpsych.2004.01.006

[19] Richardson, J.C., Newby, T. The role of students' cognitive engagement in online learning. American Journal of Distance Education, 2006, vol. 20(1), pp. 23-37. https://doi.org/ $\underline{10.1207 / \mathrm{s} 15389286 \text { ajde2001_3 }}$

[20] Joo, K.P., Andrés, C., Shearer, R. Promoting distance learners' cognitive engagement and learning outcomes: Design-based research in the Costa Rican National University of Distance Education. International Review of Research in Open and Distributed Learning, 2014, vol. 15(6), pp. 188-210. https://doi.org/10.19173/irrodl.v15i6.1908 
Paper — Research on the Relationship between Learning Engagement and Learning Completion of...

[21] Seckman, C.A. Perceived sense of community, cognitive engagement, and learning outcomes among undergraduate nursing students enrolled in an internet-based learning course. CIN: Computers, Informatics, Nursing, 2014, vol. 32(10), pp. 482-489. https://doi.org/ $\underline{10.1097 / C I N .0000000000000076}$

[22] Li, S., Zheng, J., Lajoie, S.P. The relationship between cognitive engagement and students' performance in a simulation-based training environment: an information-processing perspective. Interactive Learning Environments, 2020, pp. 1-14. https://doi.org/10.1080/ 10494820.2020 .1848879

[23] Dogan, U. Student engagement, academic self-efficacy, and academic motivation as predictors of academic performance. The Anthropologist, 2015, vol. 20(3), pp. 553-561. https:// doi.org/10.1080/09720073.2015.11891759

[24] Sagayadevan, V., Jeyaraj, S. The role of Emotional Engagement in Lecturer-Student interaction and the Impact on Academic Outcomes of Student Achievement and Learning. Journal of the Scholarship of Teaching and Learning, 2012, vol. 12(3), pp. 1-30.

[25] Renshaw, T.L., Eklund, K., Dowdy, E., Jimerson, S.R., Hart, S.R., Earhart, J., Jones, C.N. Examining the relationship between scores on the behavioral and emotional screening system and student academic, behavioral, and engagement outcomes: An investigation of concurrent validity in elementary school. The California School Psychologist, 2019, vol. 14(1), pp. 81-88. https://doi.org/10.1007/BF03340953

[26] Wara, E., Aloka, P.J., Odongo, B.C. (2018). Relationship between emotional engagement and academic achievement among Kenyan secondary school students. Academic Journal of Interdisciplinary Studies, vol. 7(1), pp. 107. https://doi.org/10.2478/ajis-2018-0011

[27] Lee, H., Doh, Y.Y. A study on the relationship between educational achievement and emotional engagement in a gameful interface for video lecture systems. In 2012 International Symposium on Ubiquitous Virtual Reality, 2012, vol. (pp. 34-37). IEEE. https://doi.org/ 10.1109/ISUVR.2012.21

[28] Gonida, E.N., Voulala, K., Kiosseoglou, G. Students' achievement goal orientations and their behavioral and emotional engagement: Co-examining the role of perceived school goal structures and parent goals during adolescence. Learning and Individual differences, 2009, vol. 19(1), pp. 53-60. https://doi.org/10.1016/j.lindif.2008.04.002

[29] Shih, S.S. The relation of self-determination and achievement goals to Taiwanese eighth graders' behavioral and emotional engagement in schoolwork. The Elementary School Journal, 2008, vol. 108(4), pp. 313-334. https://doi.org/10.1086/528974

[30] Mih, V., Mih, C., Dragoş, V. Achievement goals and behavioral and emotional engagement as precursors of academic adjusting. Procedia-Social and Behavioral Sciences, 2015, vol. 209, pp. 329-336. https://doi.org/10.1016/j.sbspro.2015.11.243

[31] Garn, A.C., Simonton, K., Dasingert, T., Simonton, A. Predicting changes in student engagement in university physical education: Application of control-value theory of achievement emotions. Psychology of Sport and exercise, 2017, vol. 29, pp. 93-102. https://doi. org/10.1016/j.psychsport.2016.12.005

[32] Regueiro, B., Núñez, J.C., Valle, A., Piñeiro, I., Rodríguez, S., Rosário, P. Motivational profiles in high school students: Differences in behavioural and emotional homework engagement and academic achievement. International Journal of Psychology, 2018. vol. 53(6), pp. 449-457. https://doi.org/10.1002/ijop.12399

[33] Chen, I.S. Computer self-efficacy, learning performance, and the mediating role of learning engagement. Computers in Human Behavior, 2017, vol. 72, 362-370. https://doi.org/10. $\underline{1016 / j . c h b .2017 .02 .059}$ 
Paper — Research on the Relationship between Learning Engagement and Learning Completion of...

[34] Lorenzet, S. J., Salas, E., \& Tannenbaum, S. I. Benefiting from mistakes: The impact of guided errors on learning, performance, and self-efficacy. Human Resource Development Quarterly, 2005, vol. 16(3), pp. 301-322. https://doi.org/10.1002/hrdq.1141

[35] Chang, C.S., Liu, E. Z.F., Sung, H.Y., Lin, C.H., Chen, N.S., Cheng, S.S. Effects of online college student's Internet self-efficacy on learning motivation and performance. Innovations in education and teaching international, 2014, vol. 51(4), pp. 366-377. https://doi.org/10. $1080 / 14703297.2013 .771429$

[36] Lee, P.C., Mao, Z. The relation among self-efficacy, learning approaches, and academic performance: An exploratory study. Journal of Teaching in Travel \& Tourism, 2016, vol. 16(3), pp. 178-194. https://doi.org/10.1080/15313220.2015.1136581

[37] Arnold, J.J., Johnson, L.M., Tucker, S.J., Malec, J.F., Henrickson, S.E., Dunn, W.F. Evaluation tools in simulation learning: Performance and self-efficacy in emergency response. Clinical Simulation in Nursing, 2009, vol. 5(1), pp. e35-e43. https://doi.org/10.1016/j.ecns. $\underline{2008.10 .003}$

\section{$7 \quad$ Author}

Wenjing You is a Lecturer in Department of Social Work and Social Management, Youth College of Political Science of Inner Mongolia Normal University, Inner Mongolia, 010000, China.

Article submitted 2021-10-01. Resubmitted 2021-11-29. Final acceptance 2021-12-03. Final version published as submitted by the author. 